\title{
Do we need to screen and treat pregnant women for subclinical hypothyroidism? A cross sectional study in a rural tertiary centre in Kerala, India
}

\author{
Radha K. R.*, Nishu Sugunan, Resmy C. R.
}

Department of Obstetrics and Gynecology, Government Medical College, Thrissur, Kerala, India

Received: 04 January 2017

Revised: 06 January 2017

Accepted: 27 January 2017

\section{*Correspondence:}

Dr. Radha K. R.,

E-mail: dr.radhakr@ rocketmail.com

Copyright: () the author(s), publisher and licensee Medip Academy. This is an open-access article distributed under the terms of the Creative Commons Attribution Non-Commercial License, which permits unrestricted non-commercial use, distribution, and reproduction in any medium, provided the original work is properly cited.

\begin{abstract}
Background: Hypothyroidism (HT) is associated with maternal and perinatal morbidity. Subclinical HT rather than overt occur in pregnancy, because overt HT causes infertility. Treatment of overt HT was beneficial in reducing the fetal and maternal complications, Usefulness of correcting subclinical hypothyroidism was doubtful, hence Universal screening of pregnant women was not recommended.

Methods: Cross sectional study, conducted in the department of obstetrics and gynecology, Government Medical College, Thrissur, Kerala, India. 50 consecutive cases of subclinical hypothyroidism in pregnancy were analyzed for Thyroid function, antenatal, natal, postnatal complications. Perinatal complications, including neonatal hypothyroidism also noted. Statistical analysis done using computer software Epi info3.4. Data expressed in its frequency and percentage, continuous data in mean.

Results: All women in the study group received levothyroxine during pregnancy from time of diagnosis. At the time of delivery $84 \%$ women were euthyroid and $16 \%$ hypothyroid. Complications like anemia $36 \%$, abruption $4 \%$, and postpartum hemorrhage $6 \%$ showed a statistically significant association, while pre-eclampsia $20 \%$, preterm labor $22 \%$ had no statistically significant association. Comparing the women who are euthyroid as a result of levothyroxine supplementation to women inadequately treated, complications like anemia (33\% versus 50\%, p value 0.042), abruption ( $0 \%$ versus $4 \%$, p value 0.023$)$, PPH (2\% versus $6 \%, \mathrm{p}$ value 0.014$)$ were significantly less in well controlled.

Conclusions: Significant association was noted between inadequately treated hypothyroidism and maternal complications like anaemia, placental abruption, placenta previa, PPH, preterm delivery, and caesarean section rate for foetal distress. Universal screening of pregnant women for thyroid status is recommended.
\end{abstract}

Keywords: Maternal morbidity, Perinatal outcome, Subclinical hypothyroidism

\section{INTRODUCTION}

Thyroid disease is the second commonest endocrine disorder next to diabetes mellitus affecting women of child bearing age. ${ }^{1}$ About $2-5 \%$ of all pregnant women are reported to have some degree of hypothyroidism. ${ }^{2}$ Overt hypothyroidism complicates 2-3 per 1000 pregnancies. ${ }^{3}$ Subclinical hypothyroidism is a prevalent condition which may go unrecognised and has the potential to develop adverse maternal and fetal outcome. ${ }^{4}$

Thyroid hormone plays a vital role in development of placenta and fetus. ${ }^{5}$ In early pregnancy the embryo depends on maternal thyroid supply via placenta. Foetal 
thyroid functions start at 10 -12 weeks of gestational age. ${ }^{6}$ Maternal thyroxin accounts for $30 \%$ of thyroxin in foetal serum at term.

Overt hypothyroidism is diagnosed when an abnormally high thyrotropin level was accompanied by low thyroxin level. ${ }^{7}$ Sub clinical hypothyroidism defined as elevated serum thyrotropin level accompanied by normal serum thyroxin concentration. TSH plays a central role in screening and diagnosis of hypothyroidism. The thyroid adapts through changes in thyroid hormone economy and in the regulation of the hypothalamic-pituitary-thyroid axis. ${ }^{8}$ Both the lower normal limit and the upper normal limit of serum TSH are decreased by about 0.1 $0.2 \mathrm{mIU} / \mathrm{L}$ and $1.0 \mathrm{mIU} / \mathrm{L}$, respectively, compared with the customary TSH reference interval of 0.4-4.0 mIU/L of nonpregnant women. Serum TSH and its reference range gradually rise in the second and third trimesters, but it is noteworthy that the TSH reference interval remains lower than in nonpregnant women. ${ }^{9}$ Hypothyroidism in pregnancy is diagnosed where TSH value is in the following range in each of the trimesters : first trimester, 0.1-2.5 mIU/L; second trimester, 0.2 $3.0 \mathrm{mIU} / \mathrm{L}$; third trimester, 0.3-3.0 mIU/L. ${ }^{9,10}$

Pregnancy complications with hypothyroidism include increased incidence of preeclampsia, abruptio placentae, anemia, and preterm labour. ${ }^{2,3}$ Unexplained still birth, fetal distress, low birth weight, neonatal hypothyroidism are perinatal complications. ${ }^{2,3}$ Women with previously diagnosed hypothyroidism already on thyroxin replacement therapy, when pregnant need dose increment. ${ }^{11}$ Treatment of overt hypothyroidism is proven to be beneficial in eliminating maternal and fetal complications. ${ }^{11}$ Most thyroid dysfunction that occurs in pregnancy is subclinical. But the lack of clear data for efficacy of treatment of sub clinical hypothyroidism, controversy exists regarding the need for universal screening for thyroid dysfunction during pregnancy verses testing only symptomatic or high risk women. ${ }^{11,12}$

Various guidelines like American Association of Clinical Endocrinologist and the American thyroid Association 2012, Endocrine society 2012, The Cochrane Collaboration 2010, ACOG does not recommend

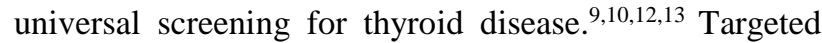
thyroid function testing of pregnant women at high risk for thyroid disease only would miss about one third of women with overt and sub clinical thyroid disease. ${ }^{14,15}$

\section{METHODS}

This was a cross sectional study conducted in the Department of Obstetrics and Gynecology, Government Medical College, Thrissur, Kerala, India over a period of one year. Objective of the study was to analyze maternal complications and perinatal outcome of women diagnosed to have subclinical hypothyroidism and also to determine the occurrence of neonatal hypothyroidism among the neonates of these women.
All pregnant women detected to be hypothyroid prior to or during pregnancy and were biochemically euthyroid or hypothyroid were included in the study. Women with multiple pregnancy, IUGR, and overt diabetes, history of thyroid surgery were excluded from study. Assuming the prevalence rate of hypothyroidism between $3-5 \%$ in pregnant women a sample size of 50 was taken. Diagnostic criteria was decided according to the endocrine society (USA) guidelines. According to these criteria, women with increased TSH (upper limit 10mIU/l) and normal T3, T4 Value is classified as having sub clinical hypothyroidism and those with increased TSH and low T3, T4 is termed as overt hypothyroidism. TSH value of $10 \mathrm{mIU} / \mathrm{L}$ or greater with normal T3, T4 was included in overt hypothyroidism. In neonate TSH value of $>20$ is considered abnormal who is tested after 72 hours of birth. ${ }^{16}$ All details of women were collected on a structured questionnaire after getting their consent. Age, parity, socioeconomic status, BMI, were noted. Details age of present pregnancy like duration of pregnancy, occurrence of gestational hypertension, preeclampsia, PPROM, abruption, placenta previa. Apart from routine investigations all are tested for thyroid function. Initial dose of thyroxin, need for increasing dose, discontinuation of drug during pregnancy, thyroid status at time of delivery were also noted. Women are followed up till delivery. Gestational age at delivery, mode of delivery, indication for caesarean section, maternal and fetal outcome were noted. After delivery neonatal examination was done to determine the APGAR score, gestational age, birth weight, fetal growth restriction, congenital anomalies. Neonatal thyroid status was checked after 72 hours of delivery.

Statistical analysis was done using Epi info 3.4. Data are expressed in its frequency and percentage. Continuous data are expressed as mean (standard deviation). To elucidate the associations and comparisons between different parameters chi square test, and Fishers test were used as non-parametric test wherever possible. Data was compared with our hospital statistics for the general obstetric population.

\section{RESULTS}

The total no of obstetric admission in the study period of one year in the hospital was 2794 out of which 71 had thyroid function abnormality (which include both overt and sub clinical hypothyroidism) making a prevalence of hypothyroidism in pregnancy as $2.54 \%$. Out of these 71 women 50 were having subclinical hypothyroidism and data of these women were analysed. The distribution of socio demographic variables like age, parity, BMI of the study group shown in Table 1 .

$90 \%$ of women were within 20 to 34 years, of them $46 \%$ of the subjects were primigravida and $54 \%$ were multigravidae. Among the 50 patients, $32 \%$ of the women are overweight and $10 \%$ obese. 26 women $(52 \%)$ were found to be hypothyroid during pregnancy while 24 
(48\%) were hypothyroid on treatment before pregnancy (confirmed with their initial investigation records). Fifteen women $(62.5 \%)$ who were already on replacement therapy needed dose increment. The mean thyroxin dose increment required was $65.5 \mathrm{mg}$ to $103 \mathrm{mg}$. In 42 women (84\%) hypothyroidism was well controlled with treatment and were euthyroid at the time of delivery (Figure 1). Among the 8 women (16\%) who were hypothyroid at time of delivery, three of them had discontinued treatment and in the remaining five women, hypothyroidism was detected recently and the women delivered within one month of treatment. The obstetric outcomes of euthyroid and hypothyroid women at the time of delivery were compared. On analysing the past obstetric events in the 27 multigravidae, 13 women $(48.1 \%)$ had experienced adverse pregnancy outcome in the previous pregnancies namely miscarriage $44.4 \%$ and still birth $3.7 \%$. Among these 50 patients, $12 \%$ had taken treatment for infertility. The maternal complication in the present pregnancy of these 50 women encountered were analysed. Anemia (36\%), preeclampsia (20\%), preterm delivery $(22 \%)$ were the commonest maternal complication noted (Table 2). The association between anaemia in relation to the thyroid status at delivery showed that $36 \%$ of hypothyroid women were anaemic out of which $16 \%$ had mild anaemia and $20 \%$ moderate anaemia. 3 had resistant anaemia not responding to parenteral iron therapy.

Table 1: Age, parity and body mass index of women with hypothyroidism.

\begin{tabular}{|c|c|c|c|}
\hline \multicolumn{2}{|l|}{ Variables } & $\begin{array}{l}\text { Frequency } \\
n=50\end{array}$ & Percentage \\
\hline \multirow{5}{*}{$\begin{array}{l}\text { Age of the } \\
\text { women (years) }\end{array}$} & $<20$ & 2 & $4 \%$ \\
\hline & $20-24$ & 11 & $22 \%$ \\
\hline & $25-29$ & 22 & $44 \%$ \\
\hline & $30-34$ & 12 & $24 \%$ \\
\hline & $>35$ & 3 & $6 \%$ \\
\hline \multirow{4}{*}{ Parity } & Primi & 23 & $46 \%$ \\
\hline & Para 1 & 21 & $42 \%$ \\
\hline & Para 2 & 4 & $8 \%$ \\
\hline & Para 3 & 2 & $4 \%$ \\
\hline \multirow{3}{*}{ BMI } & Normal & 29 & $58 \%$ \\
\hline & $\begin{array}{l}\text { Over } \\
\text { weight }\end{array}$ & 16 & $32 \%$ \\
\hline & Obese & 5 & $10 \%$ \\
\hline
\end{tabular}

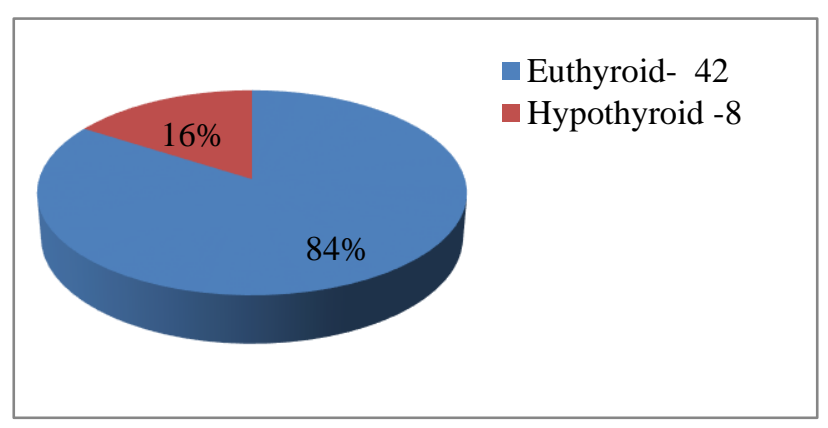

Figure 1: Thyroid control at delivery.
The occurrence of anaemia among euthyroid and hypothyroid women in the group were compared and it was found that $50 \%$ of hypothyroid women and $33 \%$ of Euthyroid women had anaemia, which was found to be statistically significant with a p value 0.042 (Table 3 ).

Table 2: Maternal complications in pregnant hypothyroid women.

\begin{tabular}{|c|c|c|}
\hline Complications & $\begin{array}{l}\text { Number of women } \\
\mathbf{n}=\mathbf{5 0}\end{array}$ & Percentage \\
\hline Anaemia & 18 & $36 \%$ \\
\hline $\begin{array}{l}\text { Gestational } \\
\text { hypertension }\end{array}$ & 3 & $6 \%$ \\
\hline Preeclampsia & 10 & $20 \%$ \\
\hline $\begin{array}{l}\text { Placental } \\
\text { abruption }\end{array}$ & 2 & $4 \%$ \\
\hline Placenta previa & 2 & $4 \%$ \\
\hline Preterm delivery & 11 & $22 \%$ \\
\hline $\begin{array}{l}\text { Postpartum } \\
\text { hemorrhage }\end{array}$ & 3 & $6 \%$ \\
\hline
\end{tabular}

Table 3: Thyroid status and anaemia.

\begin{tabular}{|llll|}
\hline $\begin{array}{l}\text { Thyroid } \\
\text { status }\end{array}$ & Anaemia status & Total \\
\hline $\begin{array}{l}\text { Euthyroid } \\
(42)\end{array}$ & $28(66.7 \%)$ & $14(33.3 \%)$ & $42(100 \%)$ \\
\hline $\begin{array}{l}\text { Hypothyroid } \\
(8)\end{array}$ & $4(50 \%)$ & $4(50 \%)$ & $8(100 \%)$ \\
\hline Total & $32(64 \%)$ & $18(36 \%)$ & $50(100 \%)$ \\
\hline
\end{tabular}

$\mathrm{P}$ value 0.042

The occurrence of preeclampsia in the euthyroid and hypothyroid women at delivery was compared and found to have no statistically significant association, $\mathrm{p}$ value 0.331 (Table 4).

Table 4: Thyroid status and preeclampsia.

\begin{tabular}{|l|l|l|l|}
\multirow{2}{*}{ Thyroid status } & \multicolumn{2}{l}{ Pre-eclampsia } & \multirow{2}{*}{ Total } \\
\cline { 2 - 3 } & Absent & Present & \\
\hline Euthyroid & $35(83.3 \%)$ & $7(16.7 \%)$ & 42 \\
\hline Hypothyroid & $5(62.5 \%)$ & $3(37.5 \%)$ & 8 \\
\hline Total & $40(80 \%)$ & $10(20 \%)$ & 50 \\
\hline P & & & \\
\hline
\end{tabular}

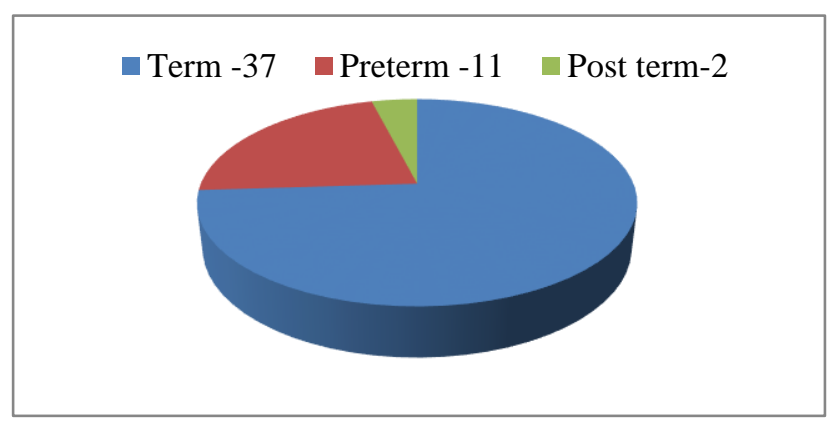

Figure 2: Gestational age at delivery $\mathbf{n = 5 0}$. 
Out of these 50 subjects $37(74 \%)$ delivered at term, 11 (22\%) had preterm delivery and 2(4\%)delivered post term (Figure 2). 26 (52\%) women had normal vaginal delivery, 22 (44\%) needed caesarean section and 2 (4\%) needed assisted vaginal delivery.

Out of 50 neonates $44 \%$ had complications, low birth weight $(28 \%)$, prematurity $(22 \%)$, were the commonest complications (Table 5). There were 3 cases of perinatal loss (1 stillbirth and 2 neonatal deaths), all 3 in the hypothyroid women.

8 babies $(20 \%)$ of the 42 euthyroid women were born prematurely, while 3 babies $(37.5 \%)$ of the 8 hypothyroid women were born prematurely, which was statistically significant with $\mathrm{p}$ value -0.014 (Table 6).
Table 5: Neonatal outcome.

\begin{tabular}{|c|c|c|}
\hline & $\begin{array}{l}\text { Number of } \\
\text { babies } n=50\end{array}$ & Percentage \\
\hline No complications & 28 & $56 \%$ \\
\hline Prematurity & 11 & $22 \%$ \\
\hline Low birth weight & 14 & $28 \%$ \\
\hline Neonatal jaundice & 4 & $8 \%$ \\
\hline $\begin{array}{l}\text { Meconium } \\
\text { aspiration }\end{array}$ & 3 & $6 \%$ \\
\hline Stillbirth & 1 & $2 \%$ \\
\hline Congenital anomaly & - & - \\
\hline ICU admission & 6 & $12 \%$ \\
\hline NND & 2 & $4 \%$ \\
\hline
\end{tabular}

Table 6: Thyroid status and prematurity.

\begin{tabular}{|c|c|c|c|c|}
\hline \multirow{2}{*}{\multicolumn{2}{|c|}{ Thyroid status }} & \multicolumn{2}{|c|}{ Gestational age } & \multirow{3}{*}{$\begin{array}{l}\text { Total } \\
42\end{array}$} \\
\hline & & \multirow{2}{*}{$\begin{array}{l}>\mathbf{3 7} \text { weeks } \\
34\end{array}$} & \multirow{2}{*}{$\begin{array}{l}<37 \text { weeks } \\
8\end{array}$} & \\
\hline & Number of patients $(n=42)$ & & & \\
\hline Euthyroid & Percentage & $81 \%$ & $19 \%$ & $100 \%$ \\
\hline \multirow{2}{*}{ Hypothyroid } & Number of patients $(n=8)$ & 5 & 3 & 8 \\
\hline & Percentage & $62.50 \%$ & $37.50 \%$ & $100 \%$ \\
\hline \multirow{2}{*}{ Total } & Number of babies & 39 & 11 & 50 \\
\hline & Percentge & $78 \%$ & $22 \%$ & $100 \%$ \\
\hline
\end{tabular}

Chi square 6.096, $\mathrm{P}$ value 0.014 .

\section{DISCUSSION}

The prevalence of hypothyroidism was noted to be $2.54 \%$ in our obstetric population during the study period and was in accordance with other reports. ${ }^{1}$ Where as high prevalence was reported from various parts of India. ${ }^{3}$ The mean age of women in this study was 27.2 years $(\mathrm{SD} \pm 4.55) .46 \%$ of women were primigravida and $54 \%$ multigravida. $10 \%$ of our study population were obese and $32 \%$ were over-weight. $26 \%$ of women in the study group has history of poor obstetric outcome in the form of abortions (24\%), unexplained still birth (2\%), 12\% had taken treatment for infertility. Maternal complications were seen in the form of anaemia in $18(36 \%)$, PIH in 13 $(26 \%)$, placental abruption in $2(4 \%)$, Placenta previa in $2(4 \%)$ and postpartum haemorrhage in $3(6 \%)$ cases. Occurrence of preeclampsia was $37.5 \%$ in inadequately controlled thyroid status, where as it was $16.5 \%$ in adequately controlled but it was not statistically significant ( $\mathrm{P}$ value 0.331 ). Various other studies have shown a significant association between hypothyroidism and gestational hypertension and preeclampsia. ${ }^{17,19}$ There were 2 cases of abruption both occurred in patient with inadequately controlled hypothyroidism which was statistically significant (P value-0.023). Out of 3 cases of post-partum hemorrhage, 2 women had inadequately controlled hypothyroidism which was statistically significant ( $p$ value 0.014 ). The occurrence of pregnancy induced hypertension in this study was $26 \%$, which is comparable to our hospital statistics $(21.6 \%)$. There is two times higher incidence of abruption and placenta previa in hypothyroid patients in our study compared to our hospital statistics where abruption and placenta previa accounts for $2.1 \%$ and $1.8 \%$ respectively.

Mode of delivery in this study, the overall rate of caesarean section was $44 \%$, which was comparable with our hospital statistics of overall CS rate $(42 \%){ }^{18}$

But in our study $18 \%$ of caesarean section were due to fetal distress which was higher when compared with the hospital statistics which was $7 \%$ (statistically significant). Increased incidence of fetal distress was also reported by sahu et al in his study. ${ }^{20}$ There is high incidence of fetal distress in pregnancy with hypothyroidism and it was suggested that hypothyroidism may exert irreversible effect on the fetus and placenta in early pregnancy that impair their subsequent ability to tolerate stress there by increasing the incidence of fetal distress in labour.

In this study 14 neonates (28\%) had low birth weight; out of which majority were preterm babies $(78 \%)$ which were statistically significant. There was one still birth at 32 weeks of gestation. None of the babies had congenital malformation. Three babies had neonatal jaundice which required phototherapy, but statistically not significant. 
The overall neonatal survival rate was $94 \%$ with perinatal mortality rate of $6 \%$ which was statistically not significant. There was only one case of still birth which was due to abruptio placentae at 32 weeks. The women had hypothyroidism which was not under control. There were two cases of neonatal death, both are early preterm babies. Both had subclinical hypothyroidism not under control. In this study woman with adequately controlled hypothyroidism, neonatal outcome was $100 \%$ satisfactory.

All neonates had normal thyroid function. Thyroid function tests could not be performed in 3 babies (one case of still birth, and two cases of neonatal death).

\section{CONCLUSION}

Out of 50 subclinical hypothyroid women $84 \%$ were euthyroid and $16 \%$ had hypothyroidism which was not under control at the time of delivery. The evolution of pregnancies including maternal complications and perinatal outcome did not depend upon whether hypothyroid is subclinical or overt but mainly on the treatment received and whether the patient was euthyroid or hypothyroid at the time of delivery. $62.5 \%$ of women who were on levothyroxine prior to pregnancy needed dose increment during pregnancy to maintain euthyroid state.

There was statistically significant association between inadequately controlled hypothyroidism and maternal complications like anemia, placental abruption, placenta previa, postpartum hemorrhage, and pre-term delivery. There was also increased incidence of fetal distress in women with hypothyroidism which resulted in significant increase in caesarean section.

Regarding neonatal outcome there was statistically significant association between in adequately controlled hypothyroidism and low birth weight due to prematurity. Neo natal outcome was satisfactory in women who were adequately treated and euthyroid at the time of delivery. Hence it may be prudent to say that it is beneficial to treat all women with hypothyroidism including subclinical hypothyroidism, hence screening all pregnant women for thyroid dysfunction is recommended. Small sample size in this study maybe a limiting factor. Considering this as a pilot study, we are planning for a larger case control study based on this.

\section{ACKNOWLEDGEMENTS}

Author would like to thank the Institutional Research committee for supporting us through the study.

Funding: No funding sources

Conflict of interest: None declared

Ethical approval: The study was approved by the Institutional Ethics Committee

\section{REFERENCES}

1. Ramprasad M, Bhattacharyya SS, Bhattacharyya A. Thyroid disorders in pregnancy. Indian J Endocrinology Metabolism. 2012;16(8):167.

2. Casey BM, Dashe JS, Wells CE, McIntire DD, Byrd W, Leveno KJ, Cunningham FG. Subclinical hypothyroidism and pregnancy outcomes. Obst Gynec. 2005;105(2):239-45.

3. Sahu MT, Das V, Mittal S, Agarwal A, Sahu M. Overt and subclinical thyroid dysfunction among Indian pregnant women and its effect on maternal and fetal outcome. Archives Gynec Obst. 2010;281(2):215-20.

4. Dhanwal DK, Prasad S, Agarwal AK, Dixit V, Banerjee AK. High prevalence of subclinical hypothyroidism during first trimester of pregnancy in North India. Indian J Endocrinology Metabolism. 2013;17(2):281.

5. Ahmed OM, Gareib AW, Bakry AM, Tawab SA, Ahmed RG. Thyroid hormones states and brain development interactions. International J Developmental Neurosci. 2008;26(2):147-209.

6. James SR, Franklyn JA, Kilby MD. Placental transport of thyroid hormone. Best Practice Research Clinic Endocrin Metab. 2007;21(2):253-64.

7. Staub JJ, Althaus BU, Engler H, Ryff AS, Trabucco $\mathrm{P}$, Marquardt K, et al. Spectrum of subclinical and overt hypothyroidism: effect on thyrotropin, prolactin, and thyroid reserve, and metabolic impact on peripheral target tissues. Am J Med. 1992;92(6):631-42.

8. Kumar A, Gupta N, Nath T, Sharma JB, Sharma S. Thyroid function tests in pregnancy. Indian $\mathrm{J}$ Med Sci. 2003;57(6):252.

9. Green SA, Abalovich M, Alexander E, Azizi F, Mestman J, Negro R, et al. Guidelines of the American thyroid association for the diagnosis and management of thyroid disease during pregnancy and postpartum. Thyroid. 2011;21(10):1081-125.

10. Garber JR, Cobin RH, Gharib H, Hennessey JV, Klein I, Mechanick JI, et al. Woeber for the American Association of Clinical Endocrinologists and American thyroid association taskforce on hypothyroidism in adults KA clinical practice guidelines for hypothyroidism in adults: cosponsored by the American association of clinical endocrinologists and the American thyroid association. Thyroid. 2012;22(12):1200-35.

11. Alexander EK, Marqusee E, Lawrence J, Jarolim P, Fischer GA, Larsen PR. Timing and magnitude of increases in levothyroxine requirements during pregnancy in women with hypothyroidism. New England J Med. 2004;351(3):241-9.

12. Surks MI, Ortiz E, Daniels GH, Sawin CT, Col NF, Cobin RH, et al. Subclinical thyroid disease: scientific review and guidelines for diagnosis and management. JAMA. 2004;291(2):228-38.

13. Pearce SH, Brabant G, Duntas LH, Monzani F, Peeters RP, Razvi S, et al. ETA guideline: 
management of subclinical hypothyroidism. European Thyroid J. 2013;2(4):215-28.

14. Lazarus J, Brown RS, Daumerie C, Dydejczyk A, Negro R, Vaidya B. European thyroid association guidelines for the management of subclinical hypothyroidism in pregnancy and in children. European Thyroid Journal. 2014;3(2):76-94.

15. Vaidya B, Anthony S, Bilous M, Shields B, Drury J, Hutchison S, et al. Detection of thyroid dysfunction in early pregnancy: universal screening or targeted high-risk case finding? J Clinic Endocrino Metab. 2007;92(1):203-7.

16. Manglik AK, Chatterjee N, Ghosh G. Umbilical cord blood TSH levels in term neonates: a screening tool for congenital hypothyroidism. Indian Pediatr. 2005;42(10):1029-32.

17. Leung AS, Millar LK, Koonings PP, Montoro M, Mestman JH. Perinatal outcome in hypothyroid pregnancies. Obstet Gynec. 1993;81(3):349-53.
18. Annul obstetrics statistics 2015-Department of Obstetrics and gynecology, Government medical college Thrissur (unpublished Data).

19. Kumar LS, Leelabati T. Subclinical Hypothyroidism and Pregnancy Outcomes. Annals of International Medical and Dental Res. 2015;1(3):324-6.

20. Sahu MT, Das V, Mittal S, Agarwal A, Sahu M. Overt and subclinical thyroid dysfunction among Indian pregnant women and its effect on maternal and fetal outcome. Archives gynecology and obstetrics. 2010;281(2):215.

Cite this article as: Radha KR, Sugunan N, Resmy CR. Do we need to screen and treat pregnant women for subclinical hypothyroidism? A cross sectional study in a rural tertiary centre in Kerala, India. Int $\mathbf{J}$ Reprod Contracept Obstet Gynecol 2017;6:781-6. 